\title{
DESENVOLVIMENTO VEGETATIVO E PRODUC̃̃O DE VARIEDADES DE CANA-DE-ACCÚCAR EM RELAÇÃO À DISPONIBILIDADE HÍDRICA E UNIDADES TÉRMICAS
}

\author{
Vegetative development and production of sugarcane varieties \\ as a function of water availability and thermic units
}

\author{
Alexsandro Claudio dos Santos Almeida ${ }^{1}$, José Leonaldo Souza², Iêdo Teodoro ${ }^{3}$, \\ Geraldo Veríssimo Souza Barbosa ${ }^{4}$, Gilson Moura Filho ${ }^{5}$, Ricardo Araújo Ferreira Júnior ${ }^{6}$
}

\begin{abstract}
RESUMO
Objetivou-se, neste trabalho, avaliar padrões de crescimento e de produção de variedades de cana-de-açúcar (Saccharum officinarum L.) com os graus-dias e disponibilidade hídrica, durante os cultivos de cana-planta e cana-soca, na região dos Tabuleiros Costeiros Alagoano. O trabalho foi desenvolvido na área experimental de Agrometeorologia da Universidade Federal de Alagoas, Rio Largo-AL, num solo classificado como Latossolo Amarelo coeso argissólico. Utilizou-se o delineamento experimental de blocos cazualizados com cinco repetições e quatro tratamentos: variedades RB92579, RB931530, RB93509 e SP79-1011. As variáveis da cultura utilizadas foram: perfilhamento, altura da planta, índice de área foliar (IAF), acúmulo de matéria seca no colmo e produção final. Foram encontradas diferenças significativas entre as médias de perfilhamento das variedades em todas as épocas amostradas, de forma geral o maior perfilhamento foi observado na variedade RB92579. O crescimento das plantas apresentou curvas de formato sigmoidal, com três fases distintas. Na fase de estabelecimento da cultura, apesar de ter ocorrido ótima disponibilidade hídrica, o crescimento foi lento. Na fase de crescimento vegetativo as plantas não cresceram em potencial, porque houve deficiências hídricas. A fase final ocorreu entre 1500 e 2015 GD na canaplanta e 950 e 1800 GD na cana-soca. A variedade RB92579 alcançou valores de IAF superiores a 3, $\log$ o aos 600 GD nos dois ciclos, permanecendo o restante dos ciclos acima desse valor, contribuindo para uma melhor eficiência no uso da água e para o maior acúmulo de matéria seca.
\end{abstract}

Termos para indexação: Crescimento, variedades, perfilhamento, variáveis meteorológicas, Saccharum officinarum L.

\begin{abstract}
This work had the aim of evaluating the growth standard and yield of different sugarcane (Saccharum officinarum L.) varieties with meteorogical parameter, during the plant and ratoon crop cane in Mesas regions of Alagoas. This work was carried out in an experimental area of Agrometeorology used a randomized outline with five repetition and four treatments: varieties RB92579, RB931530, SP79-1011 e RB93509, in the Agrarian Center of University Federal of Alagoas in Northeast of Brazil, Rio Largo - AL, in a United Argissolico Yellow Latossolo soil. The plant parameter utilized to measure the growth were: tillering, plant height, leaf area index (LAI), dry mater accumulation in stalk and yield sugarcane. No differences were observed among tillering media from varieties in all samplings, and in general, the variety RB92579 obtained the biggest tillering. The sugarcane growth showed sigmoidal shape curve, with three different phases. In the crop initial phase, although it occurred great water conditions the sugarcane growth was slow. In the elongation phase the sugarcane didn't grow in potential, due the occurred water deficit in this phase. The last phase occurred between 1500 e 2015 GD in plant cane and 950 e 1800 GD in ratoon crop. The variety RB92579 obtained LAI values of 3 very early (in $600 \mathrm{GD}$ ), this contributed to improve the water use efficient and to accumulate more dry matter. The variety RB92579 obtained the biggest tillering ant height of stalk, a result of that, it obtained the biggest yield sugarcane.
\end{abstract}

Index terms: Growth, variety, tillering, meteorogical elements, Saccharum officinarum L.

(Recebido em 2 de agosto de 2007 e aprovado em 4 de junho de 2008)

\footnotetext{
Engenheiro Agrônomo, Mestrando em Irrigação e Drenagem - Departamento de Engenharia Rural/DER - Escola Superior de Agricultura Luiz de Queiroz/ ESALQ - Universidade de São Paulo/USP - Avenida Pádua Dias, 11 - Cx. P. 9 - 13418-900 - Piracicaba, SP - almeidaacs@yahoo.com.br

${ }^{2}$ Meteorologista, Doutor em Agronomia, Professor Associado - Laboratório de Agrometeorologia e Irrigação - Instituto de Ciências Atmosféricas/ICA Universidade Federal de Alagoas/UFAL - Cidade Universitária - 57072-970 - Maceió, AL - jls@ccen.ufal.br

${ }^{3}$ Engenheiro Agrônomo, Doutorando em Engenharia Agrícola, Professor Adjunto - Laboratório de Irrigação - Centro de Ciências Agrárias/CECA Universidade Federal de Alagoas/UFAL - Cidade Universitária - 57072-970 - Maceió, AL - iteodoro@ceca.ufal.br

${ }^{4}$ Engenheiro Agrônomo, Mestre em Estatística, Professor Adjunto - Centro de Ciências Agrárias/CECA - Programa de Melhoramento Genético da Canade-Açúcar - Universidade Federal de Alagoas/UFAL - Br 104 Norte, Km 85 - 57100-000 - Rio Largo, AL - gvsb@fapeal.br

${ }^{5}$ Engenheiro Agrônomo, Doutor em Agronomia, Professor Associado - Centro de Ciências Agrárias/CECA - Programa de Melhoramento Genético da Cana-de-Açúcar - Universidade Federal de Alagoas/UFAL - Br 104 Norte, Km 85 - 57100-000 - Rio Largo, AL - gmf@fapeal.br

${ }^{6}$ Engenheiro Agrônomo - Laboratório de Agrometeorologia e Irrigação - Instituto de Ciências Atmosféricas/ICA - Universidade Federal de Alagoas/UFAL Cidade Universitária - 57072-970 - Maceió, AL - Ricardo_ceca@hotmail.com
} 


\section{INTRODUÇÃO}

A preocupação crescente por fontes de energias renováveis e menos poluentes tem elevado a demanda de biocombustíveis, dentre os quais se destaca o álcool proveniente da cana-de-açúcar. Com isso, a área de cultivo da cana-de-açúcar tem se expandido muito, sobretudo no centrosul brasileiro. Por outro lado, regiões tradicionalmente canavieiras, como as regiões dos Tabuleiros Costeiros e Zona da Mata do Nordeste, não dispõem mais de área para expansão, tornando-se imprescindível manejar a cultura corretamente para aumentar a produtividade. O manejo adequado implica em conhecer os padrões de crescimento de cada variedade, fazendo com que as fases de máximo desenvolvimento coincidam com os períodos de maior disponibilidade hídrica e radiação solar, permitindo que a cultura expresse todo seu potencial genético (KEATING et al., 1999; STONE et al., 1999). Para a cana-de-açúcar, uma precipitação pluvial anual a partir de $1.000 \mathrm{~mm}$, bem distribuída, é suficiente para a obtenção de altas produções. Isso implica em que o manejo hídrico seja realizado com eficiência - com suprimentos hídricos adequados durante o desenvolvimento vegetativo (principalmente nas fases de germinação, perfilhamento e alongamento dos colmos) e alguma restrição no período de maturação, para forçar o repouso fisiológico e o enriquecimento em sacarose (INMAN-BAMBER \& SMITH, 2005).

A região canavieira de Alagoas tem na precipitação pluvial o principal fator limitante da produtividade. Embora em termos dos totais anuais (em $1500-2000 \mathrm{~mm}$ ) esse suprimento hídrico se enquadre dentro das exigências da cana-de-açúcar (INMAN-BAMBER \& SMITH, 2005), há um excedente no outono-inverno (a precipitação equivale a $70 \%$ do total anual) e uma deficiência na primavera-verão (SOUZA et al., 2004) coincidindo com a fase de desenvolvimento da cana-de-açúcar que tem maior exigência hídrica. Essa característica agroclimática contribui muito para as baixas produções alcançadas nessa região.

A temperatura do ar é outro elemento meteorológico que também afeta o crescimento da cana-de-açúcar. Quando a temperatura ultrapassa $20^{\circ} \mathrm{C}$, há um aumento na taxa de crescimento da cultura, sendo que a faixa de $25^{\circ} \mathrm{C}$ a $33^{\circ} \mathrm{C}$ é a mais favorável ao desenvolvimento vegetativo. Bachi \& Souza (1978) observaram no Sul/Sudeste brasileiro que temperaturas entre $18^{\circ} \mathrm{C}$ a $20^{\circ} \mathrm{C}$, são críticas para o crescimento da cultura.

A identificação da capacidade produtiva de diferentes variedades e a investigação dos efeitos do manejo da cultura são geralmente realizadas através da análise de crescimento pela avaliação de alguns parâmetros morfológicos das plantas (altura, número de plantas por metro, área foliar e produção). O crescimento da parte aérea da cana (INMAN-BAMBER et al., 2002; MACHADO et al., 1982; OLIVEIRA et al., 2005; ROBERTSON et al., 1996) ocorre de forma sigmoidal e pode ser dividida em três etapas: fase inicial, em que o crescimento é lento; fase de crescimento rápido, que ocorre pelo surgimento e alongamento de entrenós, onde se acumula $75 \%$ da fitomassa total; fase final, de crescimento lento. Portanto, a determinação do comprimento das fases em cada variedade é importante para ajustá-las aos períodos de maior exigência hídrica, com condições de suprimento hídrico adequadas.

Considerando que a produtividade da cana-de-açúcar na região canavieira alagoana é muito dependente das condições ambientais, objetivou-se, neste trabalho, avaliar padrões de crescimento, desenvolvimento e produção de quatro variedades de cana-de-açúcar com os graus-dias e disponibilidade hídrica durante os cultivos de cana-planta e cana-soca, na região dos Tabuleiros Costeiros de Alagoas.

\section{MATERIAL E MÉTODOS}

O trabalho foi desenvolvido na área experimental de Agrometeorologia do Centro de Ciências Agrárias da Universidade Federal de Alagoas, Campus Delza Gitaí, Rio Largo, (09²8'02"S; 3549'43"W; 127m), região dos Tabuleiros Costeiros de Alagoas. O solo da área é classificado como Latossolo Amarelo coeso argissólico de textura média/argilosa, topografia amena e declividade inferior a $2 \%$. As variedades de cana-de-açúcar avaliadas foram a SP79-1011, RB92579, RB93509 e RB931530, em dois ciclos de cultivo (cana-planta e cana-soca). As variedades RB foram lançadas em 2003 pelo Programa de Melhoramento Genético de Cana-de-açúcar da UFAL, e atualmente a variedade RB92579 é mais plantada no Nordeste, ocupando $30 \%$ da área plantada. $\mathrm{O}$ delineamento experimental utilizado foi o de blocos casualizados, com cinco repetições e 4 tratamentos. O experimento foi conduzido numa área de $500 \mathrm{~m}^{2}$, subdividida em parcelas de cinco linhas de cultivo com 4 metros lineares.

A área recebeu uma calagem na base de duas toneladas de calcário dolomítico por hectare $(\mathrm{PRNT}=85 \%)$. O preparo do solo constou de 1 gradagem pesada +2 gradagens niveladoras e sulcamento. O plantio foi realizado em outubro de 2003, com uma adubação de fundação de 70 $\mathrm{kg}$ de $\mathrm{N} \mathrm{ha}^{-1}, 60 \mathrm{~kg}$ de $\mathrm{P}_{2} \mathrm{O}_{5}$ ha $^{-1}$ e $120 \mathrm{~kg}$ de $\mathrm{K}_{2} \mathrm{O}$ ha $^{-1}$. A calagem e adubação foram determinadas através da análise química do solo. A adubação da cana-soca foi na mesma quantidade da cana-planta. As irrigações realizadas nas fases de estabelecimento nos dois ciclos foram baseadas na evapotranspiração da cultura (ETc), calculada multiplicandose a evapotranspiração de referência (ETo) pelo Kc da FAO. 
Para avaliação do perfilhamento (número de colmos. $\mathrm{m}^{-2}$ ) e altura dos colmos foram realizadas contagens e medições do comprimento a cada 15 dias, após plantio (DAP) e após o corte (DAC), utilizando-se todos os colmos da linha central de cada parcela. Para avaliação da área foliar (AF) foram realizadas 10 amostragens periódicas a cada 30 dias, a partir dos 60 DAP e DAC, selecionando-se 15 plantas ao acaso, em cada parcela. O IAF foi determinado através da metodologia de Francis et al. (1969), sendo as curvas correlacionadas com os graus-dia. A determinação das fases de crescimento foi realizada de acordo com as taxas de crescimento da cultura: fase 1- estabelecimento - taxas de crescimento entre 0,2 a $0,9 \mathrm{~cm} /$ dia, fase 2 - crescimento linear - maior que 0,9 $\mathrm{cm} /$ dia e fase 3 - maturação- menor que $0,2 \mathrm{~cm} /$ dia.

O método dos graus-dia baseia-se na premissa de que a planta necessita de certa quantidade de energia, representada pela soma de graus térmicos acima de uma temperatura-base, para completar determinada fase fenológica. Os graus-dia acumulados foram determinados pelo programa GD-CANA (MOURA-FILHO et al., 2005), baseados na metodologia proposta por Liu et al. (1999).

Para determinação da produção final de colmos e da fitomassa de colmos da cultura foi feita uma amostragem coletando-se 1,5 m lineares, com três repetições. Após a determinação da massa total de matéria fresca, em cada amostra foi retirada uma subamostra, depois de ter sido triturada. As subamostras foram secadas em estufa de ventilação forçada, com temperatura de $60-65^{\circ} \mathrm{C}$, até que a massa permanecesse constante. Com esses resultados foi estimada a produção média de matéria seca do colmo (t.ha $\left.{ }^{-1}\right)$.

Os elementos meteorológicos foram medidos em uma estação automática de aquisição de dados (Micrologger CR10X). Através dos dados obtidos foi feita a análise do balanço hídrico e temperatura do ar sobre o desenvolvimento das quatro variedades. $\mathrm{O}$ balanço hídrico foi realizado baseado no modelo de Thornthwaite \& Mather (1957), sendo a evapotranspiração de referência (ETo) obtida através do método de Penman-Monteith-FAO (ALLEN et al., 1998) e a evapotranspiração da cultura (ETc) calculada multiplicando-se a ETo pelo Kc da FAO (ALLEN et al., 1998). Os dados das variáveis das plantas foram submetidos à análise de variância, utilizando o teste F. As médias foram comparadas pelo teste de média de Tukey, a $5 \%$ de probabilidade.

\section{RESULTADOS E DISCUSSÃO}

\section{Perfilhamento}

$\mathrm{O}$ aumento do perfilhamento foi acentuado da emergência até 120 DAP ou 800 GD na cana-planta e 60 DAC ou 350 GD na cana-soca, quando atingiram o pico (Tabela 1). Essa maior rapidez das variedades na obtenção

Tabela 1 - Evolução do perfilhamento nas variedades RB92579, RB93509, SP79-1011 e RB93509, nos cultivos de canaplanta e cana-soca, em função dos graus-dia, dias após plantio (DAP) e dias após o corte (DAC).

\begin{tabular}{|c|c|c|c|c|c|c|c|}
\hline \multirow{3}{*}{ Variedades } & \multicolumn{7}{|c|}{ População (Perfilhos.m ${ }^{-2}$ ) em cana-planta } \\
\hline & \multicolumn{7}{|c|}{ Dias após Plantio (DAP) } \\
\hline & 30 & 60 & 90 & 120 & 150 & 200 & 360 \\
\hline RB92579 & $3,9 \mathrm{a}$ & $13,2 \mathrm{a}$ & $19,2 \mathrm{a}$ & 27,6 a & $18,5 \mathrm{a}$ & $14,1 \mathrm{a}$ & $10,9 \mathrm{a}$ \\
\hline RB93509 & $2,7 \mathrm{ab}$ & $8,5 \mathrm{~b}$ & $14,5 \mathrm{ab}$ & $19,1 \mathrm{~b}$ & $10,3 \mathrm{~b}$ & $9,70 \mathrm{~b}$ & $8,30 \mathrm{~b}$ \\
\hline SP79-1011 & $1,9 \mathrm{a}$ & $6,0 \mathrm{~b}$ & $13,7 \mathrm{~b}$ & $17,9 \mathrm{~b}$ & $13,6 \mathrm{ab}$ & $10,5 \mathrm{~b}$ & $8,20 \mathrm{~b}$ \\
\hline RB931530 & $1,6 \mathrm{~b}$ & $5,3 \mathrm{~b}$ & $13,1 \mathrm{~b}$ & $17,8 \mathrm{~b}$ & $11,7 \mathrm{~b}$ & $9,50 \mathrm{~b}$ & $7,40 \mathrm{~b}$ \\
\hline $\mathrm{CV}(\%)$ & 22,3 & 25,3 & 18 & 12,4 & 20,5 & 13,6 & 9,8 \\
\hline Média geral & 4,05 & 8,3 & 15 & 20,6 & 13,5 & 11 & 8,7 \\
\hline \multirow{3}{*}{ Variedades } & \multicolumn{7}{|c|}{ População (Perfilhos.m ${ }^{-2}$ ) em cana soca } \\
\hline & \multicolumn{7}{|c|}{ Dias Após o Corte (DAC) } \\
\hline & 30 & 60 & 90 & 120 & 150 & 200 & 360 \\
\hline RB92579 & $28,0 \mathrm{a}$ & $40,5 \mathrm{a}$ & $14,8 \mathrm{a}$ & $14,4 \mathrm{a}$ & $13,8 \mathrm{a}$ & $13,3 \mathrm{a}$ & $12,7 \mathrm{a}$ \\
\hline RB93509 & $10,9 \mathrm{~b}$ & $17,9 \mathrm{~b}$ & $10,8 \mathrm{~b}$ & $10,8 \mathrm{~b}$ & $10,8 \mathrm{~b}$ & $10,6 \mathrm{~b}$ & $10,5 \mathrm{~b}$ \\
\hline SP79-1011 & $10,7 \mathrm{~b}$ & $15,0 \mathrm{~b}$ & $9,5 \mathrm{~b}$ & $9,5 \mathrm{~b}$ & $9,5 \mathrm{~b}$ & $9,2 \mathrm{~b}$ & $9,0 \mathrm{bc}$ \\
\hline RB931530 & $13,7 \mathrm{~b}$ & $18,2 \mathrm{~b}$ & $9,5 \mathrm{~b}$ & $9,5 \mathrm{~b}$ & $9,5 \mathrm{~b}$ & $9,1 \mathrm{~b}$ & $8,3 \mathrm{c}$ \\
\hline $\mathrm{CV}(\%)$ & 36,35 & 22,51 & 11,12 & 8,8 & 8,27 & 13,8 & 10,5 \\
\hline Média geral & 15,8 & 23 & 11 & 11 & 11 & 10 & 10 \\
\hline
\end{tabular}

(1) Médias seguidas das mesmas letras não diferem entre si, a 5\% de probabilidade do teste de Tukey.

${ }^{(2)} \mathrm{CV}$ : Coeficiente de variação 
do pico de perfilhamento na cana-soca deve-se ao sistema radicular já estar estabelecido, enquanto na cana-planta o sistema radicular vai se desenvolver. Isso também se deve ao fato das condições ambientais terem sido ótimas, através da combinação entre suprimento hídrico adequado e temperaturas altas $\left(25,5^{\circ} \mathrm{C}\right.$ e $\left.27^{\circ} \mathrm{C}\right)$ no $1^{\circ}$ e $2^{\circ}$ ciclo, respectivamente (Figura 1). Esses valores de temperatura situaram-se dentro da faixa ideal $\left(25^{\circ} \mathrm{C}\right.$ a $\left.33^{\circ} \mathrm{C}\right)$, para essa fase vegetativa (KEATING et al., 1999; LIU et al., 1999). O pico de perfilhamento obtido aos 120 DAP coincide com os valores obtidos por Machado et al. (1982) e Oliveira et al. (2005), que encontraram máximo perfilhamento variando de 20 a 30 plantas $\mathrm{m}^{-2}$, entre 3,5 a 4 meses depois do plantio, em cana-planta. Porém, o pico na cana-soca diferiu dos valores de Alvares \& Castro (1999) e Inman-Bamber (1994), que observaram o valor máximo aos 500GD.

Após a ocorrência do pico de perfilhamento (Tabela 1), ocorreu um acentuado declínio, com uma redução natural aproximada de $50 \%$ na população de plantas, estabilizando por volta de 1600 GD - exigência térmica dentro da faixa $1200 \mathrm{GD}$, a $1800 \mathrm{GD}$ conforme Liu et al. (1999), para ocorrência desse declínio em cana-plana, por causa da competição por luz nas plantas de uma mesma touceira. Entretanto, na cana-soca, a redução do perfilhamento ocorreu com apenas 600GD, com um suprimento hídrico adequado, porém a temperatura média do ar situou-se ao redor de $23^{\circ} \mathrm{C}$, um pouco abaixo da faixa de temperatura ideal, tendo contribuído para reduzir o número de perfilhos por área. Durante o período de redução na cana-planta, a temperatura não foi um fator limitante, entretanto ocorreu deficiência hídrica entre os decêndios 14 e 18 (Figura 1). Portanto, a baixa variância nos dados e a similaridade entre as variedades, sugere que o início da mortalidade dos perfilhos é um estádio fenológico previsível da cultura da cana-de-açúcar.

\section{Altura da planta e índice de área foliar (IAF)}

A variação do IAF e da altura das qı tro variedades de cana-de-açúcar mostrou três fases (Figuras 2 e 3 ). A mesma tendência tem sido observada em outras variedades por outros autores em outras regiões do Brasil e do mundo (GAVA et al., 2001; INMAN-BAMBER, 1994; MACHADO et al., 1982; OLIVEIRA et al., 2004; ROBERTSON et al., 1996). A $1^{\text {a }}$ fase (estabelecimento da cultura) ocorreu com 750GD desde o plantio no cultivo planta, e com 600GD desde o corte na cana-soca. Nessa fase, o crescimento foi lento em função da pequena área foliar por colmo em plantas novas, quando as folhas estavam pequenas e pouco expandidas. Nessa fase, o suprimento hídrico foi adequado nos dois cultivos, pois as chuvas e a irrigação (Tabela 2) foram suficientes para atender à demanda, e a temperatura média do ar situou-se próximo a $25^{\circ} \mathrm{C}$ (Figura 1), dentro da faixa ideal de $24^{\circ} \mathrm{C}$ a $30^{\circ} \mathrm{C}$ (LIU et al., 1999), para surgimento e expansão foliar da cultura, visto que o IAF é altamente dependente dessas duas variáveis.

Na segunda fase, o crescimento se mostrou rápido e linear e ocorreu entre os 750 e 1500 GD na cana-planta e entre 600 e 950 GD na cana-soca, na qual os IAF aumentaram de forma continuada até aproximadamente 3,5 na cana-planta e 4,5 na cana-soca. Essa fase foi responsável por $70 \%$ do crescimento total da cana, alcançando valores médios de $1,70 \mathrm{~m}$ de altura na canaplanta e 1,84 m na cana-soca (Tabela 2). Esse aspecto de desenvolvimento da cultura foi observado por Alvarez \& Castro (1999), Inman-Bamber et al. (2002) e Machado et al. (1982), onde a elongação do colmo coincide com o aumento

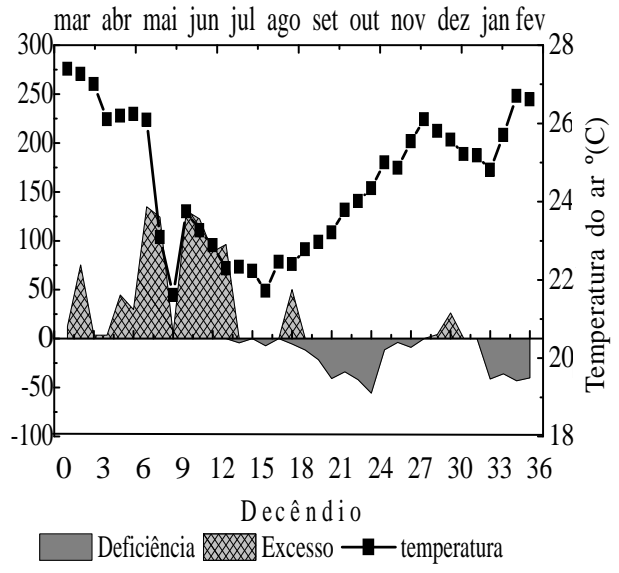

Figura 1 - Balanço hídrico e temperatura do ar, durante os períodos de cultivos de cana-planta e cana-soca. 

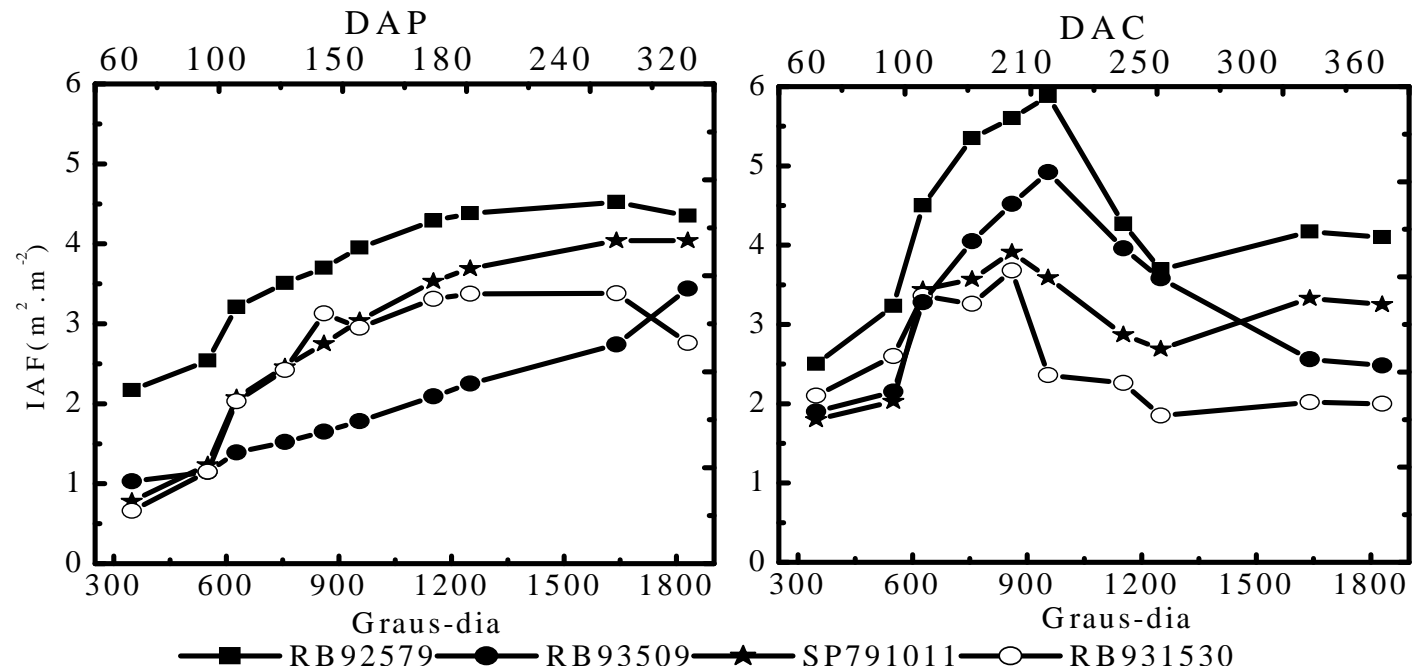

Figura 2 - Evolução do índice de área foliar (IAF), nas variedades RB92579, RB93509, SP79-1011 e RB93509, nos cultivos de cana-planta e cana-soca, em função dos graus-dia dias, após plantio (DAP) e dias após o corte (DAC).

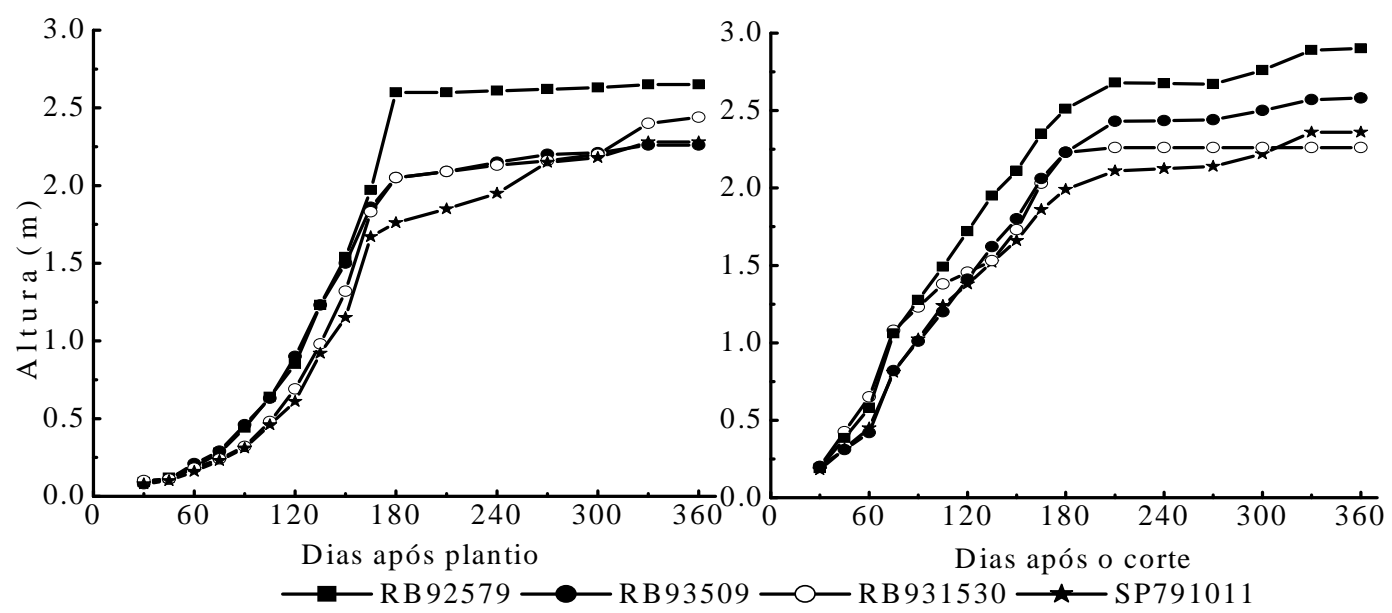

Figura 3 - Evolução da altura do colmo (m) das variedades, nos cultivos de cana-planta e cana-soca, em função dos dias após plantio (DAP) e dias após o corte (DAC).

Tabela 2 - Evapotranspiração da cultura (ETc, mm), evapotranspiração real (ETr, mm), precipitação pluvial mais irrigação $(\mathrm{P}+\mathrm{I}, \mathrm{mm})$, crescimento médio das quatro variedades de cana $(\mathrm{cm})$ e taxa de crescimento média $(\mathrm{cm} /$ dia $)$ nas três fases (1- estabelecimento, 2- crescimento linear e 3- maturação) de crescimento da cana-de-açúcar nos cultivos de canaplanta e cana-soca, na região de Rio Largo-AL.

\begin{tabular}{|c|c|c|c|c|c|c|c|c|c|c|}
\hline \multirow{2}{*}{$\begin{array}{l}\text { Fases da } \\
\text { cultura }\end{array}$} & \multicolumn{2}{|c|}{$\begin{array}{l}\text { ETc } \\
(\mathrm{mm})\end{array}$} & \multicolumn{2}{|c|}{$\begin{array}{c}\mathrm{ETr} \\
(\mathrm{mm})\end{array}$} & \multicolumn{2}{|c|}{$\begin{array}{l}\mathrm{P}+\mathrm{I} \\
(\mathrm{mm})\end{array}$} & \multicolumn{2}{|c|}{$\begin{array}{l}\text { Crescimento } \\
\text { (altura-cm) }\end{array}$} & \multicolumn{2}{|c|}{$\begin{array}{c}\text { Taxa crescimento } \\
(\mathrm{cm} / \mathrm{dia})\end{array}$} \\
\hline & planta & soca & planta & soca & planta & soca & planta & soca & planta & soca \\
\hline Fase 1 & 371.0 & 380 & 370.9 & 380 & 682.6 & 614 & 60 & 53 & 0,66 & 0,88 \\
\hline Fase 2 & 609.2 & 430 & 347.6 & 375 & 540.4 & 840 & 170 & 184 & 1,2 & 1,18 \\
\hline Fase 3 & 467.9 & 774 & 463.6 & 503 & 1424.2 & 491 & 20 & 15 & 0,12 & 0,1 \\
\hline TOTAL & 1448 & 1584 & 1182 & 1258 & 2647 & 1954 & 250 & 252 & 0,63 & 0,6 \\
\hline
\end{tabular}


da área foliar. No início desse período (decêndios 8 a 13) a cana-planta foi provida de boa disponibilidade hídrica que favoreceu o crescimento contínuo do IAF e, por conseguinte do colmo. Entretanto, no final do período (decêndio 14 a 18) ocorreu déficit hídrico (Figura 1), não permitindo que o IAF na cana-planta alcançasse os altos valores obtidos na cana-soca para essa mesma fase, mesmo com a temperatura do ar na cana-soca ao redor de $22^{\circ} \mathrm{C}$. As variedades alcançaram IAF acima de 3 no intervalo de 7 a 8 meses na cana-planta e 4 a 7 meses na cana-soca, portanto dentro do intervalo do $5^{\circ}$ ao $8^{\circ}$ mês, mencionado por Teruel et al. (1997), que também observou que a cana-soca atinge o máximo de IAF mais rapidamente, entretanto ele permanece alto por pouco tempo. Porém, o estresse hídrico de aproximadamente $190 \mathrm{~mm}$ nos meses de setembro e outubro (entre os decêndios 20 e 25) contribuiu para redução dos IAF na cana-soca (Figura 2).

A fase final (maturação) ocorreu entre 1500 e 2015 GD na cana-planta e 950 e 1800 GD na cana-soca. Essa fase caracterizou-se pela estabilização do IAF na cana-planta e pela redução seguida de estabilização dos IAF na canasoca. $\mathrm{O}$ crescimento da cultura foi bastante lento, devido ao direcionamento dos fotoassimilados para o acúmulo de sacarose, em detrimento da redução do IAF e elongação do colmo (KEATING et al., 1999). O processo de redução da taxa de crescimento do colmo ocorreu de forma natural na cana-planta, sem aparente influência ambiental, pois não ocorreu estresse hídrico no período (figura 1) e a temperatura média situou-se próxima da faixa ideal. Embora no final do ciclo da cana-de-açúcar a temperatura do ar já não exerça tanta influência como em outras fases da cultura (LIU et al., 1999). Entretanto na cana-soca ocorreu deficiência hídrica nos meses de outubro e novembro (entre os decêndios 23 e 28), reduzindo ainda mais a taxa de crescimento, $3 \%$ a menos em relação à cana-planta na mesma fase.
Os valores de IAF das quatro variedades foram caracterizados pela similaridade no padrão das curvas de crescimento. É importante ressaltar que embora os valores de IAF tenham variado, o formato sigmoidal das curvas de crescimento é universal (INMAN-BAMBER et al., 2002). A variedade RB92579 alcançou valores de IAF superiores a 3 logo aos 600 GD nos dois ciclos, permanecendo o restante dos ciclos com IAF acima desse valor, contribuindo para uma melhor eficiência no uso da água (INMAN-BAMBER \& SMITH, 2005).

\section{Matéria seca acumulada no colmo e produção final}

Os acúmulos de matéria seca e produção final de colmo das quatro variedades diferiram (Tabela 3), pois a variedade RB92579 mostrou-se mais produtiva e acumulou 53 e $35 \mathrm{t} \mathrm{ha}^{-1}$ de matéria seca e $167,9 \mathrm{t} \mathrm{ha}^{-1}$ e $136 \mathrm{t} \mathrm{ha}^{-1} \mathrm{de}$ colmos no primeiro e segundo ciclo, respectivamente, diferindo estatisticamente de todas as outras variedades. As variedades RB93509, SP79-1011 e RB931530, mostraram $77 \%, 65 \%$ e $53 \%$ do acúmulo de matéria seca da variedade mais produtiva a RB92579, respectivamente. Essas diferenças de matéria seca acumuladas pelas variedades pesquisadas foram também observadas para outras variedades em trabalhos de Gava et al. (2001) e Oliveira et al. (2005).

A produção de $53 \mathrm{t} \mathrm{ha}^{-1}$ de matéria seca no colmo obtida pela variedade RB92579 é considerada ótima, baseando-se em Inmam-Bamber et al. (2002) que alcançaram produções de 50 a 68 t.ha ${ }^{-1}$ em variedades com alto potencial genético sob condições nutricionais e hídricas adequadas. Com base nos resultados da literatura e nos deste trabalho pode-se afirmar, que a variedade RB92579 foi a mais produtiva porque seu aparato fotossintético (IAF) foi maior em todos os períodos dos dois cultivos, com IAF acima de 4, garantindo-lhe maior capacidade de acúmulo de

Tabela 3 - Matéria seca acumulada no colmo e produção final de colmos de cana-de-açúcar nas variedades RB92579, RB93509, SP79-1011 e RB931530, nos ciclos de cana-planta e cana-soca, em toneladas por hectare (t.ha $\left.{ }^{-1}\right)$.

\begin{tabular}{ccccccc}
\hline \multirow{2}{*}{ Variedade } & \multicolumn{2}{c}{ perfilhamento } & \multicolumn{2}{c}{ produção de colmos $\left(\mathrm{t} \mathrm{ha}^{-1}\right)$} & \multicolumn{2}{c}{${\text { matéria seca }\left(\mathrm{t} \mathrm{ha}^{-1}\right)}$} \\
& cana-planta & soca & cana-planta & soca & cana-planta & soca \\
\hline RB92579 & $10,9 \mathrm{a}$ & $12,7 \mathrm{a}$ & $167,89 \mathrm{a}$ & $136,22 \mathrm{a}$ & $53,24 \mathrm{a}$ & $35,21 \mathrm{a}$ \\
RB93509 & $8,3 \mathrm{~b}$ & $10,5 \mathrm{~b}$ & $110,30 \mathrm{~b}$ & $115,56 \mathrm{ab}$ & $37,81 \mathrm{~b}$ & $30,10 \mathrm{a}$ \\
SP79-1011 & $8,2 \mathrm{~b}$ & $9,0 \mathrm{bc}$ & $100,57 \mathrm{~b}$ & $83,23 \mathrm{bc}$ & $31,06 \mathrm{bc}$ & $20,69 \mathrm{~b}$ \\
RB931530 & $7,4 \mathrm{~b}$ & $8,3 \mathrm{c}$ & $83,92 \mathrm{~b}$ & $76,04 \mathrm{c}$ & $23,43 \mathrm{c}$ & $17,39 \mathrm{~b}$ \\
\hline Média & 8,7 & 10 & 115,67 & 102,76 & 36,38 & 25,85 \\
CV $(\%)$ & 9,8 & 10,5 & 10,02 & 12,33 & 9,66 & 9,1 \\
\hline
\end{tabular}

${ }^{(1)}$ Médias seguidas das mesmas letras diferem entre si, a $5 \%$ de probabilidade do teste de Tukey.

${ }^{(2)} \mathrm{CV}$ : Coeficiente de variação 
fotoassimilados e aproveitamento da energia solar, e também por apresentar maior número de plantas por área.

\section{CONCLUSÃO}

Sob condições ambientais durante as estações de cultivo (cana-planta e cana-soca) a variedades RB92579 tem atributos de crescimento e produção superiores às demais. O manejo dessa variedade na região de estudo é realizado mais racionalmente quando utilizada como cana de início e meio de safra (colheita realizada nos meses de setembro-dezembro) devido as exigências térmicas e relações hídricas das interações genótipo-ambiente.

\section{AGRADECIMENTOS}

À Fapeal e ao CNPq-Pibic, pelo apoio financeiro; Ao PMGCA/CECA/UFAL, pelo apoio logístico.

\section{REFERÊNCIAS BIBLIOGRÁFICAS}

ALLEN, R. G.; PEREIRA, L. S.; RAES, D.; SMITH, M. Crop evapotranspiration: guidelines for computing crop requeriments. Roma: FAO, 1998. 328 p. (Irrigation and drainage parper, 56).

ALVAREZ, I. A.; CASTRO, P. R. C. Crescimento da parte aérea da cana crua e queimada. Scientia Agrícola, Piracicaba, v. 56, n. 4, p. 1069-1079, 1999.

BACHI, O. O. S.; SOUZA, J. A. G. C. Minimum threshold temperature for sugar cane growth. In: INTERNATIONAL SOCIETY OF SUGAR CANE TECHNOLOGISTS, 1978, São Paulo, SP.Proceedings... São Paulo, 1978. v. 2, p. 1733-1741.

FRANCIS, C. A.; RUTGER, J. N.; PALMER, A. F. E. A rapid method for leaf plant area estimation in maize (Zea mays L.). Crop Science, Madison, v. 9, p. 537-539, 1969.

GAVA, G. J. C.; TRIVELIN, P. C. O.; OLIVEIRA, M. W.; PENATTI, C. P. Crescimento e acúmulo de nitrogênio em cana-planta cultivada em solo coberto com palhada. Pesquisa Agropecuária Brasileira, Brasília, v. 36, n. 11, p. 1347-1354, nov. 2001.

INMAN-BAMBER, N. G. Temperature and seasonal effects on canopy development and light interception of sugarcane. Field Crops Research, Amsterdam, v. 36, p. 4151, 1994.

INMAN-BAMBER, N. G.; MUCHOW, R. C.; ROBERTSON, M. J. Dry partitioning of sugarcane in Australia and South
Africa. Field Crops Research, Amsterdam, v. 76, p. 71-84, 2002.

INMAN-BAMBER, N. G.; SMITH, D. M. Water relations in sugarcane and response to water deficits. Field Crops Research, Amsterdam, v. 92, p. 185-202, 2005.

KEATING, B. A.; ROBERTSON, M. J.; MUCHOW, R. C.; HUTH, N. I. Modelling sugarcane production systems I: development and performace of the sugarcane module. Field Crops Research, Amsterdam, v. 48, p. 27-36, 1999.

LIU, D. L.; KINGSTON, G.; BULL, T. A. A new technique for determining the thermal parameters of phenological development in sugarcane, including sub optimum and supra-optimum temperature regimes. Agricultural and Forest Meteorology, Amsterdam, v. 90, p. 119-139, 1999.

MACHADO, E. C.; PEREIRA, A. R.; FAHL, J. I.; ARRUDA, $\mathrm{H}$. V.; CIONE, C. Índices biométricos de duas variedades de cana-de-açúcar. Pesquisa Agropecuária Brasileira, Brasília, v. 17, n. 9, p. 1323-1329, set. 1982.

MOURA-FILHO, G.; SARMENTO, C. A. V.; SOUZA, J. L.; SILVA, L. C.; ALMEIDA, A. C. S. GD-CANA- programa cálculo de graus-dia para a cultura da cana-de-açúcar. In: CONGRESSO BRASILEIRO DE AGROMETEOROLOGIA, 14., 2005, Campinas, SP. Anais... Campinas: Sociedade Brasileira de Agrometeorologia, 2005. CD-ROM.

OLIVEIRA, R. A.; DAROS, E.; ZAMBON, J. L. C.; WEBER, H.; IDO, O. T.; ZUFELLATO-RIBAS, K. C.; KOEHLER, H. S.; SILVA, D. K. T. Crescimento e desenvolvimento de três cultivares de cana-de-açúcar, em cana-planta, no estado do Paraná. Scientia Agrária, Curitiba, v. 5, n. 1/2, p. 87-94, 2004.

OLIVEIRA, R. A.; DAROS, E.; ZAMBON, J. L. C.; WEBER, H.; IDO, O. T.; ZUFELLATO-RIBAS, K. C.; KOEHLER, H. S.; SILVA, D. K. T. Crescimento e desenvolvimento de três cultivares de cana-de-açúcar, em cana-planta, no estado do Paraná: taxas de crescimento. Scientia Agrária, Curitiba, v. 6 , n. $1 / 2$, p. $85-89,2005$.

ROBERTSON, M. J.; WOOD, A. W.; MUCHOW, R. C. Growth of sugarcane under high input conditions in tropical Australia: I. radiation use, biomass accumulation and partitioning. Field Crops Research, Amsterdam, v. 48, p. 11-25, 1996. 
SOUZA, J. L.; MOURA FILHO, G.; LYRA, R. F. F. TEODORO, I.; SANTOS, E. A.; SILVA, J. L.; SILVA, P. R. T.; CARDIM, A. H.; AMORIN, E. C. Análise da precipitação pluvial e temperatura do ar na região do tabuleiro costeiro de Maceió, AL, período de 1972-2001. Revista Brasileira de Agrometeorologia, Santa Maria, v. 12, n. 1, p. 131-141, 2004.

STONE, P. J.; SORENSEN, I. B.; JAMIESON, P. D. Effect of soil temperature on phenology, canopy development, biomass and yield of maize in a cool-temperature climate. Field Crops Research, Amsterdam, v. 48, p. 169-178, 1999.
TERUEL, D. A.; BARBIERE, V.; FERRARO JÚNIOR, L. A. Sugarcane leaf rea index modeling under different soil water condintios. Scientia Agrícola, Piracicaba, v. 54, p. 93-44, jun. 1997. Edição especial.

THORNTHWAITE, C. W.; MATHER, J. R. Instructions and tables for computing potential evapotranspiration and the water balance. Ceterton: Drexel Institute of Technology-Laboratory of Climatology, 1957. 311 p. (Publications in climatology, v. 10, n. 3). 